\title{
Studies of Cigarette Smoke Transfer Using Radioisotopically Labelled Tobacco Constituents
}

\author{
Part III: The Use of Dotrlacontane-16, 17. ${ }^{14} \mathrm{C}$ as a Marker for the Deposition \\ of Clgarette Smoke in the Respiratory System of Experimental Animals*
}

by B. R. Davis, T. H. Houseman and H. R. Roderick

Tobacco Research Council Laboratories, Harlow Hill, Harrogate, Yorkshire, England

\section{INTRODUCTION}

Quantitative information on the transfer of mainstream cigarette smoke to the respiratory system of laboratory animals may best be obtained by using radiolabelled smoke. There are, however, certain restrictions affecting the choice of radiolabelled compound for use in work of this nature. Ideally, the chosen compound should be distributed homogeneously within the tobacdo rod and in a form such that it distils directly into the particulate phase of smoke with a minimum of pyrolysis. The amount of compound distilling per unit mass of particulate matter should remain constant as the cigarette burns down. Furthermore, radiolabelled material deposited in the respiratory system of the animal as a result of exposure to the smoke should not be absorbed or metabolized.

Experiments have been reported in which hexadecane${ }^{14} \mathrm{C}(1-3)$ or Arsenic-74 (as sodium arsenate) (4) were incorporated as tracers in the cigarette rod. In our experience, incorporation of sodium arsenate into a cigarette gave rise to small quantities of arsine under the reductive conditions associated with the burning zone, and hexadecane, because of its volatility, was rapidly lost from the cigarette during storage (at $70^{\circ} \mathrm{F}$ and $60 \%$ R.H.). Thus, neither tracer seemed suitable for monitoring the intake of the particulate phase of tobacco smoke by laboratory animals.

The naturally occurring paraffinic hydrocarbon dotriacontane was selected for the present studies since it distils into the particulate phase of cigarette smoke with a minimum of pyrolysis $(2,5)$. This paper describes the development and evaluation of a method for in-

* Received for publicarion: 9th May, 1973. corporating $\mathrm{n}$-dotriacontane- $16,17-{ }^{14} \mathrm{C}$ into the particulate phase of cigarette smoke.

In earlier studies $(2,5)$, radiolabelled cigarettes were prepared by hand from tobacco sprayed with a solution of dotriacontane-16, $17^{-14} \mathrm{C}$. To achieve a more uniformly packed radiolabelled cigarette, sorted and conditioned whole cigarettes were impregnated with a solution of radiolabelled compound using the device already described (6). The mass-balance after smoking of dotriacontane-16, $17^{-14} \mathrm{C}$ activity added to cigarettes was determined using the smoking apparatus described in the preceding paper (7). Two additional studies have been made, one of the puff-by-puff transfer of dotriacontane-16, $17-{ }^{14} \mathrm{C}$ from tobacco to mainstream smoke and the other of the transfer of dotriacontane- $16,17^{-14} \mathrm{C}$ from smoke to the head and lungs of rats exposed in an Animal Smoking Apparatus developed in these Laboratories. Details are given of the construction and operation of this apparatus, which is sometimes referred to as the Harrogate Smoker $(8,9)$. An isotope dilution technique was developed for the assay of dotriacontane deposited in the heads and lungs, thus obviating the need for correction for losses of material incurred during the extraction procedure.

\section{MATERIALS AND METHODS}

\section{Radiolabelled Cigarettes}

Three separate batches of sorted and conditioned untipped cigarettes $(70 \mathrm{~mm})$ were prepared and calibrated as described by Houseman and Heneage (6). The mean total ${ }^{14} \mathrm{C}$-activity of cigarettes in each batch was found to be $0.996 \pm 0.036 \mu \mathrm{Ci}, 0.958 \pm 0.032$ and $1.18 \pm 0.04 \mu \mathrm{Ci}$ respectively ( $95 \%$ confidence limits). 


\section{Liquid Scintillation Counting}

Sample radioactivity was determined by liquid scintillation counting using conditions already described (6).

\section{Gas Chromatography}

The mass of dotriacontane in toluene extracts of smoke total particulate matter (TPM) retained by mainstream and sidestream Cambridge filter discs and by the butt was determined by gas chromatography, using conditions previously described (6).

The water content of 200:I v.v. n-propanol : ethanol extracts of mainstream TPM collected puff-by-puff was determined by a standard gas-chromatographic procedure (10).

\section{Determination of ${ }^{14} \mathrm{C}$-Activity Balance}

The mass-balance after smoking of ${ }^{14} \mathrm{C}$-activity added to cigarettes was determined using apparatus and techniques developed for nicotine- $2^{\prime}-{ }^{14} \mathrm{C}$ mass-balance studies ( 7 ). Five cigarettes each containing a mean $0.996 \mu \mathrm{Ci}$ of ${ }^{14} \mathrm{C}$-activity were smoked consecutively in the T.R.C. smoking cartridge (7). Eleven $25 \mathrm{ml}$ puffs of 2 seconds duration were taken at one minute intervals, leaving a $20 \mathrm{~mm}$ butt. Mainstream TPM was collected on a $56 \mathrm{~mm}$ Cambridge filter disc. Sidestream TPM was collected on two $115 \mathrm{~mm}$ Cambridge filter discs mounted in series and separated by a $4 \mathrm{~mm}$ spacing ring. Particulate material condensing on the walls of the smoking cartridge was included in the sidestream TPM assay. Oxidized mainstream and sidestream vapour phases were each passed through two gas-absorption bottles containing freshly prepared $1: 8$ ethanolamine : 2methoxyethanol $(50 \mathrm{ml})$. Material resistant to oxidation by Hopcalite at $200^{\circ} \mathrm{C}$ was condensed in a liquid nitrogen cooled impaction trap mounted in series with the absorption bottles.

On completion of smoking, mainstream and sidestream Cambridge filter discs, butts and the ash were individually extracted with toluene $(20 \mathrm{ml}$ : sidestream discs $50 \mathrm{ml}$ ). The smoking cartridge was rinsed out with toluene and the solution diluted to $100 \mathrm{ml}$. Vapour phase absorption bottles and cold traps were rinsed out with methanol and the solutions diluted to $100 \mathrm{ml}$ and $50 \mathrm{ml}$ respectively. Aliquots of each solution were assayed by liquid scintillation counting to determine the total ${ }^{14} \mathrm{C}$-activity transferred to that phase of tobacco smoke.

An aliquot of each TPM extract and the cartridge washings $(5 \mathrm{ml})$ containing an accurately known weight of added unlabelled dotriacontane (ca. $25 \mathrm{mg}$ ) and a trace of anthracene was passed down a column of Woelm neutral alumina (10 g, activity grade 1 ). The sample was eluted with toluene and six fractions $(5 \mathrm{ml}$ each) were collected. Aliquots of each fraction were assayed by gas chromatography and liquid scintillation counting.

\section{Puff-by-Puff Determination of TPM and $T P M-{ }^{14} C$-Activity}

Ten cigarettes each containing a mean $0.958 \mu \mathrm{Ci}$ of ${ }^{14} \mathrm{C}$-activity were smoked consecutively using apparatus and conditions described above. Mainstream TPM was collected puff-by-puff on a series of eleven $56 \mathrm{~mm}$ Cambridge filter discs which had been weighed in their holders immediately prior to use. The numbered filterdisc holders were removed and stoppered 45 seconds after the appropriate puff. Each filter was then used again to collect particulate matter from the corresponding puff of the next cigarette. Dry TPM on each of the filters was measured by the standard methods used in these laboratories (10).

The ${ }^{14} \mathrm{C}$-activity in the solutions remaining after the water determinations was assayed by liquid scintillation counting by the method described above.

\section{The Animal Smoking Apparatus}

Construction: The device consists of a smoke chamber, a vacuum unit for generating the smoke puff, and a timing motor. It is constructed of "Perspex" and brass, and is mounted on a plastics laminate-covered wooden plinth (Figure 1). A diagrammatic section view of the machine is shown in Figure 2.

Figure 1. The animal smoking apparatus.

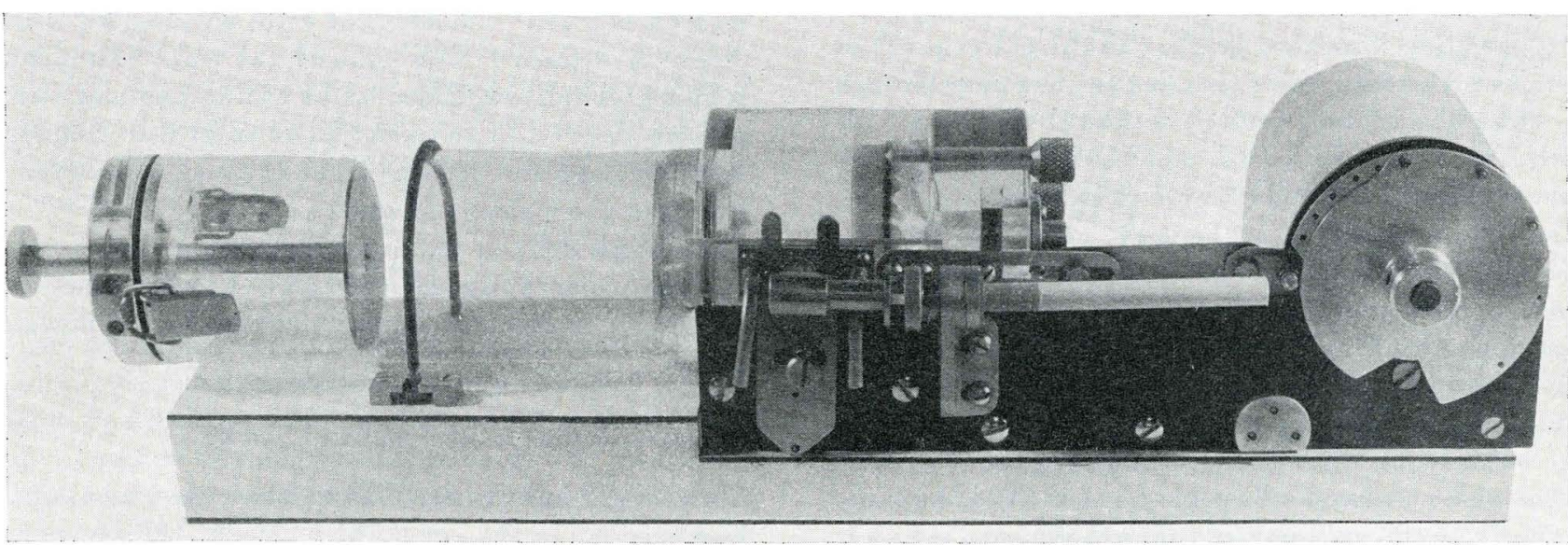


Figure 2. Sectional view of the animal smoking apparatus.

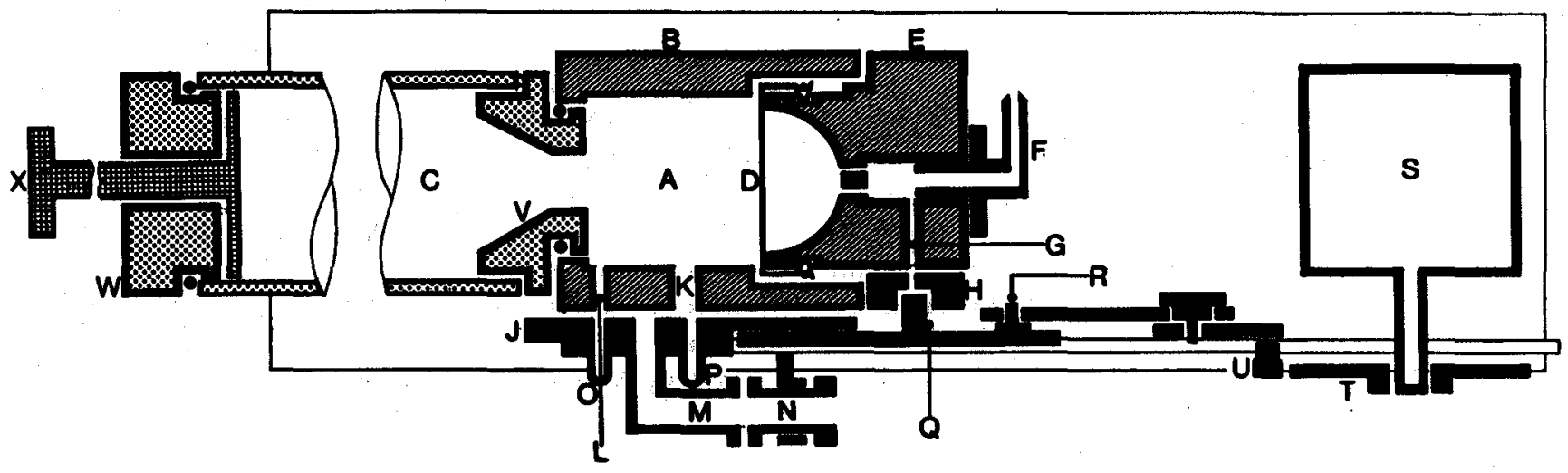

The smoke chamber (A) is a $100 \mathrm{ml}$ capacity cylindrical cavity machined in a "Perspex" block (B). One end of this chamber is closed by the animal holder (C), the joint being sealed by an " $O$ " ring. The other end is sealed by a latex diaphragm (D) on the vacuum unit which consists of a second "Perspex" block (E). This is secured to the main smoke chamber by three $2 \mathrm{BA}$ studs fitted with knurled thumb screws.

In the vacuum unit behind the latex diaphragm, there is a dome-shaped cavity $(25 \mathrm{ml})$ to which a vacuum can be applied at F. A vacuum-bleed (G) connects the system to atmosphere between puffs and is controlled by a small slide valve $(\mathrm{H})$.

Along one side of the combined smoke chamber/vacuum unit there is a machined face, on which the main slide valve $(\mathrm{J})$ operates and in which there are two ports $(\mathrm{K})$ and (L) to the smoke chamber. The slide valve is held in contact with the machined face by a spring.

Carried on the main slide valve $(\mathrm{J})$ are:

(i) A tube (M) which in the puff position seals against the back of the fixed spring-loaded cigarette holder $(N)$ and enables the smoke to pass into the smoke chamber. The tube (N) is mounted in a bracket attached to the main chassis.

(ii) Inlet and outlet tubes ( $O$ and $P$ ) through which compressed air is passed to scavenge the smoke from the chamber between puffs.

(iii) A brass strip carrying two spigots $Q$ and $R$. The former operates the slide valve $(\mathrm{H})$ and the latter is linked to the timing mechanism.

The timing unit consists of a small synchronous motor (S) operating through a gearbox to drive a cam $(\mathrm{T})$ at I r.p.m. The cam profile is such that by acting through a spring-loaded follower (U) it moves the main slide valve to allow a 2-second puff to be taken into the smoke chamber (A) and held for 15 seconds.

The animal holder is a "Perspex" tube (C), the diameter of which is chosen to suit the animals being used, with a nose cone ( $V$ ) to hold the animal's head in position. An air-tight seal is made between the holder and the smoke chamber by means of an " $O$ " ring. The other end is closed by a "Perspex" block (W) secured by quick-acting clips and also sealed by an " $\mathrm{O}$ " ring. This block carries an adjustable plunger $(X)$ to keep the animal in position throughout the experiment.
Operation: During the one minute operating cycle the moving parts of the machine occupy three positions:

(i) The Puff Position: The main slide (J) moves to allow tube $M$ to make an air-tight seal against the cigarette holder $(\mathrm{N})$. This simultaneously allows direct contact between the smoke chamber (A) and smoke tube $(M)$ and closes port $L$. The small slide valve $(H)$ is in a position where $G$ is closed to atmosphere allowing the vacuum applied at $F$ to draw the diaphragm (B) into the $25 \mathrm{ml}$ dome. The cigarette is lit during this stage of the cycle and the smoke $(25 \mathrm{ml})$ is drawn into the chamber (A).

(ii) The Hold Position: After the smoke puff has been taken the cam moves the main slide to a position in which both ports to the smoke chamber are closed and the vacuum-bleed valve remains closed. The $25 \mathrm{ml}$ puff of smoke is thus diluted with the $100 \mathrm{ml}$ of air in the chamber. This position is maintained for 15 seconds.

(iii) Smoke Clearance Position: This position is illustrated in the diagram. Air is passed through tube $O$ into the chamber $(\mathrm{A})$ and the smoke leaves tube $\mathrm{P}$. The vacuum-bleed $(G)$ is open to atmosphere and the diaphragm returns to its position.

Transfer of ${ }^{14} \mathrm{C}$-Activity to Mainstream Smoke Using the Animal Smoking Apparatus

A Cambridge filter disc and liquid nitrogen trap were interposed between the cigarette and the tube $\mathrm{N}$ for the analysis of mainstream TPM and vapour phase respectively. On completion of each smoking the filter disc was extracted with toluene $(25 \mathrm{ml})$. Scintillator solution $(20 \mathrm{ml})$ was added to the cold trap immediately prior to removal of refrigant. Aliquots of each solution were removed for determination of total radioactivity transferred to mainstream smoke.

The isotope dilution technique described in the section on mass-balance studies was used to determine the amount of unchanged dotriacontane in the particulate phase.

\section{Exposure of Rats to Radiolabelled Smoke}

Three-month old female Wistar rats were used. When first exposed to the smoke of a whole cigarette some 
Table 1. The transference of total ${ }^{14} \mathrm{C}$-activity and dotrlacontane-16, 17-14C to clgarette smoke.

\begin{tabular}{|c|c|c|c|c|}
\hline \multirow[b]{2}{*}{ Phase of smoke } & \multicolumn{2}{|c|}{ Total ${ }^{14} \mathrm{C}$-activity/cigarette } & \multicolumn{2}{|c|}{ Dotriacontane-16, $17-{ }^{14} \mathrm{C} /$ cigarette } \\
\hline & $(\mathrm{nCi})$ & $\begin{array}{l}\text { Percentage of } \\
\text { total }{ }^{14} \mathrm{C}- \\
\text { activity added } \\
\text { to cigarette* }\end{array}$ & (nCi) & $\begin{array}{l}\text { Percentage of } \\
\text { total }{ }^{14} \mathrm{C}- \\
\text { activity added } \\
\text { to cigarette }\end{array}$ \\
\hline Mainstream TPM & 201.43 & 20.2 & 197.54 & 19.8 \\
\hline Mainstream vapour & 3.09 & 0.3 & 0 & 0 \\
\hline Sidestream TPM & 451.19 & 45.3 & 437.24 & 43.9 \\
\hline Sidestream vapour & 88.64 & 8.9 & 0 & 0 \\
\hline Butt & 242.84 & 24.4 & 239.07 & 24.0 \\
\hline Ash & 0 & 0 & 0 & 0 \\
\hline Total & 987.19 & 99.1 & 873.85 & 87.7 \\
\hline
\end{tabular}

* Total ${ }^{14} \mathrm{C}$-activity extracted from whole unsmoked cigarettes $=0.996 \pm 0.036 \mu \mathrm{Ci}$ (95\% confidence limits).

animals held their breath or did not breathe normally and some died. By exposing rats to increasing amounts of smoke over a two-week period it was possible to train them to breathe reasonably normally throughout exposure to the smoke of a whole cigarette. Animals so trained were each exposed to radiolabelled mainstream smoke from one cigarette containing a mean $1.18 \mu \mathrm{Ci}$ of ${ }^{14} \mathrm{C}$-activity. $25 \mathrm{ml}$ puffs of 2 seconds duration were taken at I minute intervals, leaving a $20 \mathrm{~mm}$ butt. On completion of smoking animals were immediately killed and dissected.

Extraction of Dotriacontane-16, ${ }^{17}{ }^{14} \mathrm{C}$ from the Head, Larynx, Trachea and Lungs

Individual heads were skinned and boiled under reflux for $1 / 2$ hr. in a solution of $20 \%$ w.v. potassium hydroxide in $1: 1$ methanol : water $(250 \mathrm{ml})$ containing, added unlabelled dotriacontane $(250 \mathrm{mg})$. The solution was cooled and extracted with toluene $(3 \times 50 \mathrm{ml})$. The combined extracts were washed with water $(50 \mathrm{ml})$, dried over anhydrous sodium sulphate, filtered and reduced in volume on a rotary film evaporator.

The larynx, trachea and lungs, which were removed and assayed as a whole, were treated similarly except that half the quantities of the above reagents were used.

The concentrated extracts were passed down a column of Woelm neutral alumina (activity grade $1 / 50 \mathrm{~g}$ for heads, $4 \circ \mathrm{g}$ for lungs and trachea) and the dotriacontane was eluted with toluene. Six fractions $(25 \mathrm{ml}$ for heads, $15 \mathrm{ml}$ for lungs) were collected from each sample and the dotriacontane was determined by gas chromatography. A small quantity of anthracene was added to the extract to check the efficiency of separation. Aliquots of each fraction were also assayed by liquid scintillation counting.

\section{RESULTS AND DISCUSSION}

The uniformity of deposition, axially and radially, within the cigarettes has already been described (6).

The mass-balance after smoking of ${ }^{14} \mathrm{C}$-activity added to cigarettes was more than $99 \%$ of the mean total ${ }^{14} \mathrm{C}$-activity per cigarette. The data are shown in Table 1. Dotriacontane-16, $17^{-14} \mathrm{C}$ transferred from the tobacco solely to the particulate phase and accounted for $97-98 \%$ of the total ${ }^{14} \mathrm{C}$-activity recovered from that phase of smoke.

The mean puff-by-puff deliveries of Dry TPM and TPM ${ }^{14} \mathrm{C}$-activity (per cigarette) are shown in Figure 3. Two identical smoking experiments were carried out, the vertical bars representing the spread of the results. The observed puff-by-puff delivery of mainstream TPM ${ }^{14} \mathrm{C}$-activity is very similar to that reported by Jenkins et al. (5). The data presented in Table 2, however, show that the specific activity of Dry TPM does not remain constant throughout the smoking of a dotriacontane-labelled cigarette, but decreases with successive puffs. The mean specific activity of Dry TPM, obtained from the sum of individual puffs, did remain constant, however, values of 7.72 and $7.50 \mathrm{nCi} /$ $\mathrm{mg} /$ cigarette having been obtained in the two separate experiments and the reduction in specific activity is relatively small for the last six puffs, representing $66 \%$ of the total dry particulate matter. Thus, although dotriacontane-16, $17^{-14} \mathrm{C}$ does not fulfill all the requirements of the ideal TPM marker, it may in our opinion give a useful indication of particulate matter inhaled and retained by rats exposed to mainstream cigarette smoke.

Table 2. The puff-by-puff delivery of Dry TPM and TPM 14C-activity.

\begin{tabular}{r|c|c|c}
\hline Puff no. & $\begin{array}{c}\text { Dry TPM } \\
\text { (mg/cigarette) }\end{array}$ & $\begin{array}{c}\text { TPM 14C-activity* } \\
\text { (nCi/cigarette) }\end{array}$ & $\begin{array}{c}\text { Mean specific } \\
\text { activity of } \\
\text { Dry TPM } \\
\text { (nCi/mg) }\end{array}$ \\
\hline 1 & $1.13 \pm 0.08$ & $13.1 \pm 0.45$ & 11.6 \\
2 & $1.46 \pm 0.07$ & $12.9 \pm 0.00$ & 8.84 \\
3 & $1.40 \pm 0.01$ & $14.5 \pm 0.00$ & 10.4 \\
4 & $1.57 \pm 0.04$ & $14.1 \pm 0.30$ & 8.98 \\
5 & $1.76 \pm 0.09$ & $14.8 \pm 0.75$ & 8.41 \\
6 & $1.78 \pm 0.08$ & $13.7 \pm 0.35$ & 7.70 \\
7 & $2.17 \pm 0.01$ & $15.0 \pm 0.00$ & 6.91 \\
8 & $2.28 \pm 0.02$ & $15.8 \pm 1.45$ & 6.93 \\
9 & $2.57 \pm 0.15$ & $16.4 \pm 1.70$ & 6.38 \\
10 & $2.76 \pm 0.07$ & $17.6 \pm 0.45$ & 6.38 \\
11 & $2.87 \pm 0.04$ & $17.7 \pm 0.35$ & 6.17 \\
\hline
\end{tabular}

- Mean of two experiments, with the spread of the results. 
Flgure 3. Puft-by-puff Dry TPM dellvery.
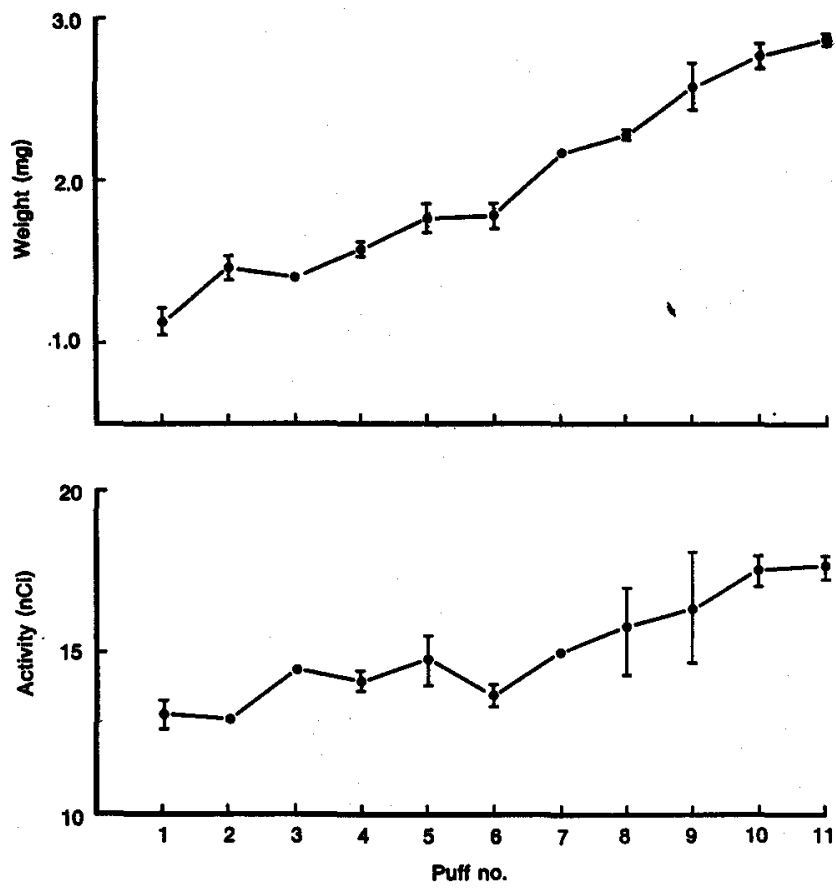

Using the Animal Smoking Apparatus, the mean figures (with $95 \%$ confidence limits) for transfer of total ${ }^{14} \mathrm{C}$-activity into mainstream TPM and the condensable vapour phase were $(18.69 \pm 2.92) \%$ and $(0.29 \pm 0.09) \%$ of the mean radioactivity per cigarette. Isotope dilution analysis of dotriacontane in the TPM extracts showed that $95.2 \%$ of mainstream TPM radioactivity was due to unchanged dotriacontane-16, $17^{14} \mathrm{C}$, representing $17.8 \%$ of that originally present in each cigarette.

Radioactivity found in the respiratory tract of animals treated in the Animal Smoking Apparatus was found to be wholly due to the intake of particulate matter. No radioactivity was detected in any of the organs removed from five rats exposed to the vapour phase only of smoke from radiolabelled cigarettes.

The mean amounts of dotriacontane-16, $17-{ }^{14} \mathrm{C}$ deposited in the head and in the larynx, trachea and lungs of each of 20 animals treated in the apparatus were found to be, respectively, $(2.2 \pm 1.4) \%$ and $(7.0 \pm 3.1) \%$ of the mean total dotriacontane-16, $17^{-14} \mathrm{C}$ content of mainstream TPM (Table 3). The limits given are the $95 \%$ confidence limits of a single measurement. The spread of results about these mean values was $\pm 64 \%$ for heads and $\pm 44 \%$ for the larynx, trachea and lungs. Since the amount of radiolabelled material transferred to the smoke chamber of the Animal Smoking Apparatus during each experiment was known with $95 \%$ confidence to be within $\pm 15.6 \%$ of the mean value (Table 3), the cases in which significantly different amounts of labelled material were found are considered to have been due to differences in the breathing patterns of the animals.

Table 3. The deposition of dotriacontane-16,17-14 C in the respiratory system of rats exposed to radiolabelled mainstream cigarette smoke.

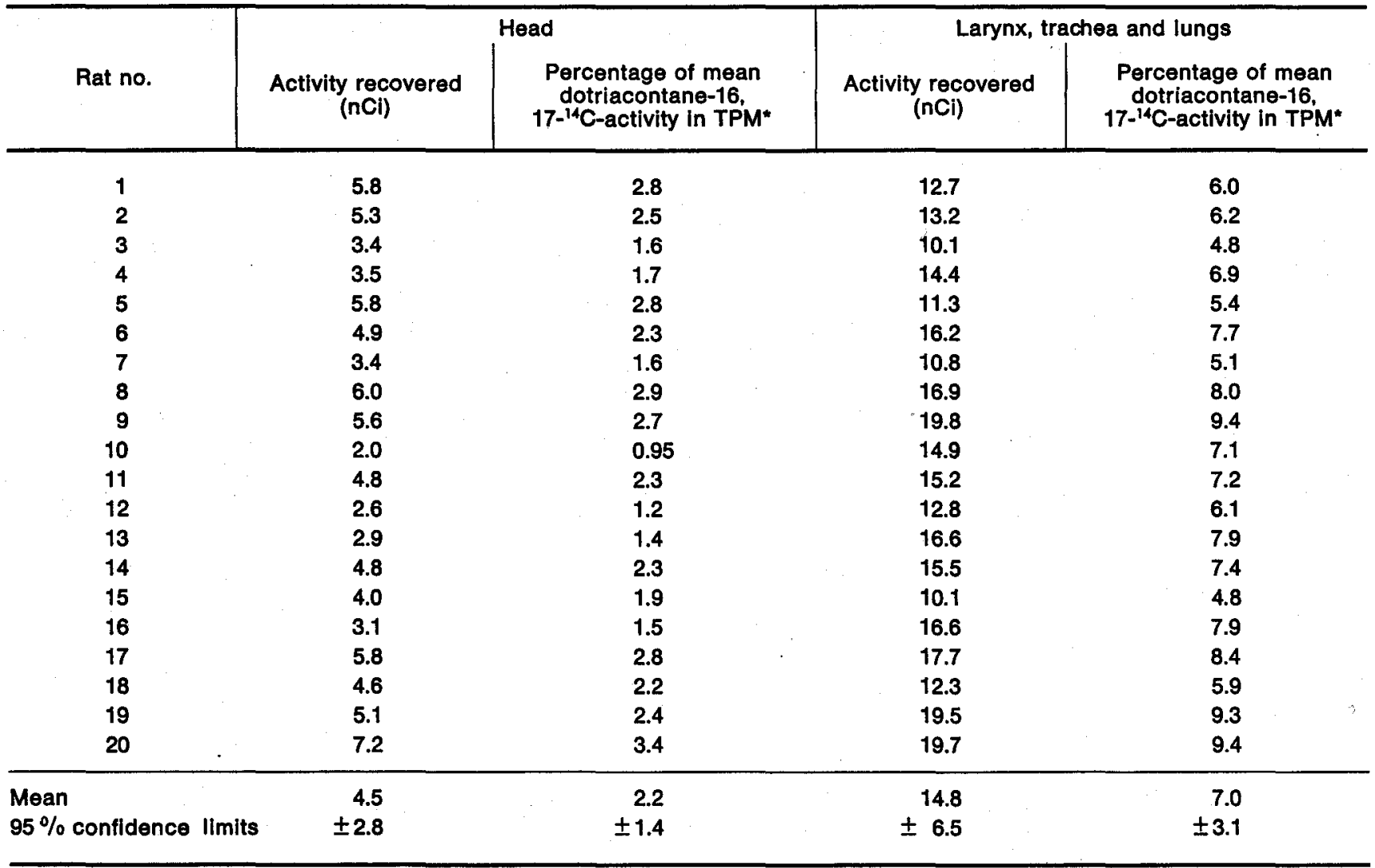

- Mean dotriacontane-16, 17-14 C activity in TPM $=210.2 \pm 32.8 \mathrm{nCl}$. 


\section{SUMMARY}

The determination of the mass-balance after smoking of dotriacontane-16, ${ }^{1} 7^{14} \mathrm{C}$ added to cigarettes is described. The radiolabelled compound was associated exclusively with the particulate phase of smoke and transferred from the tobacco with a minimum of pyrolysis.

Details are given of the construction and operation of the Animal Smoking Apparatus used for exposing rats to cigarette smoke.

Dotriacontane-16, $17 .{ }^{14} \mathrm{C}$ was used to give an indication of the amount of total particulate matter (TPM) inhaled and retained by rats exposed to mainstream smoke. The mean amounts of dotriacontane-16, $17{ }^{14} \mathrm{C}$ deposited in the head, and in the larynx, trachea and lungs of ead of 20 animals treated in the apparatus were found to be, with $95 \%$ confidence limits, $(2.2 \pm x .4) \%$ and $(7.0 \pm 3.1) \%$ respectively of the mean total dotriacontane-16, ${ }^{1} 7^{14} \mathrm{C}$ content of mainstream TPM.

\section{ZUSAMMENFASSUNG}

Die Arbeit beschreibt die Bestimmung der Masseverteilung nach dem Verrauchen von mit Dotriacontan-16, ${ }_{17}{ }^{14} \mathrm{C}$ dotierten Cigaretten. Die radioaktiv markierte Verbindung wurde ausschließlich in der Partikelphase des Rauches gefunden; sie ging mit einem Minimum an Pyrolyse vom Tabak in den Rauch iiber.

Aufbau und Arbeitsweise der Berauchungsapparatur für Tiere, in der Ratten dem Rauch von Cigaretten ausgesetzt wurden, werden beschrieben.

Mit Hilfe des Dotriacontan-16, ${ }^{17}{ }^{14} \mathrm{C}$ wurde bestimmt, wieviel Gesamtkondensat (TPM) von den Ratten, die dem Hauptstromrauch ausgesetzt wurden, eingeatmet und retiniert wurde. Die Mengen an Dotriacontan-16, ${ }_{17}{ }^{14} \mathrm{C}$, die sich im Durchschnitt in jedem der 20 in dem beschriebenen Gerät behandelten Versuchstiere und zwar im Kopf einerseits und in Larynx, Trachea und Lunge andererseits ablagerten, belaufen sich bei einem Vertrauensbereich von $95 \%$ auf $(2,2 \pm 1,4) \%$ bzw. $(7,0 \pm 3,1) \%$ des durchschnittlichen Gesamtgehaltes an Dotriacontan-16, $17-{ }^{14} \mathrm{C}$ der Partikelphase des Hauptstromrauches.

\section{RESUME}

On décrit le bilan de masse après avoir fumé le dotriacontane- $16,17-14 \mathrm{C}$ ajouté aux cigarettes. Le composé marqué radio-activement était associé uniquement à la phase particulaire de la fumée, et a été transféré du tabac avec un-minimum de pyrolyse.

On décrit en détail la construction et le maniement d'un appareil à fumer pour animaux, destiné à exposer les rats à la fumée de cigarette.

Le dotriacontane- $16,17^{-14} \mathrm{C}$ a été utilisé pour donner une indication sur la quantité de matière particulaire totale (TPM) inhalée et retenue par les rats exposés au flux principal de fumée. Les quantités moyennes de dotriacontane déposées dans la tête d'une part, dans le larynx, la trachée et les poumons d'autre part, pour chacun des vingt animaux traités dans l'appareil, était de $(2,2 \pm 1,4) \%$ et de $(7,0 \pm 3,1) \%$ respectivement (limites de confiance $95 \%$ ) de la moyenne teneur totale en dotriacontane- $16, x 7^{14} \mathrm{C}$ de la phase particulaire du flux principal de fumée.

\section{REFERENCES}

1. Dontenwill, W.: "Inhalation Carcinogenesis", U. S. Atomic Energy Commission, 1970, 389.

2. Maddox, W. L., R. B. Quincy, H. H. Ross, G. Olerich, and M. R. Guerin: 25th Tob. Chem. Res. Conf., Louisville, Kentucky, October 1971.

3. Dontenwill, W., H. P. Harke, and A. Baars: Arzneimittel-Forsch. 21 (197x) 142.

4. Holland, R. H., R. H. Wilson, D. Morris, M. S. McCall, and H. C. Lang: Cancer 11 (1958) 709.

5. Jenkins, R. W., Jr., R. H. Newman, R. D. Carpenter, and T. S. Osdene: Beitr. Tabakforsch. 5 (1970) 295.

6. Houseman, T. H., and E. Heneage: Beitr. Tabakforsch. 7 (1973) $\times 38$.

7. Houseman, T. H.: Beitr. Tabakforsch. 7 (1973) 142.

8. Bättig, K., and V. Hrubes: Z. Präventivmed. 16 (1971) 205.

9. Driscoll, P., and K. Bättig: ibid 16 (197x) 197.

10. Rothwell, K., and C. A. Grant: Research Paper II, Section 3, Tobacco Research Council, London 1972.

\section{Acknowledgement}

The authors gratefully acknowledge the co-operation of Mr. E. R. Harris in the design and construction of the Animal Smoking Apparatus.

\section{The authors' address:}

Tobacco Research Council Laboratories, Otley Road, Harlow Hill, Harrogate, Yorks., England. 